\section{Analysis of Phenethylamines and Tryptamines in Designer Drugs Using Gas Chromatography- mass Spectrometry}

\author{
Misako Takahashi, ${ }^{*}, a$ Machiko Nagashima, ${ }^{a}$ \\ Jin Suzuki, ${ }^{a}$ Takako Seto, ${ }^{a}$ Ichirou Yasuda, ${ }^{a}$ \\ and Takemi Yoshida ${ }^{b}$
}

\begin{abstract}
${ }^{a}$ Tokyo Metropolitan Institute of Public Health, 3-24-1 Hyakunin-cho, Shinjuku-ku, Tokyo 169-0073, Japan and ${ }^{b}$ Showa University, 1-5-8 Hatanodai, Shinagawa-ku, Tokyo 142-8555, Japan
\end{abstract}

(Received September 26, 2007; Accepted October 18, 2007; Published online October 31, 2007)

We developed a method for determining the following ten psychedelic phenethylamines and tryptamines by gas chromatography-mass spectrometry (GC-MS). The phenethylamines examined were 3,4,5-trimethoxyamphetamine (TMA), 2,4,5-trimethoxyamphetamine (TMA-2), 4-bromo-2,5-dimethoxyphenethylamine (2C-B), 4-iodo-2,5-dimethoxyphenethylamine (2C-I), 2,5-dimethoxy-4-ethylthiophenethylamine (2CT-2), and 2,5-dimethoxy-4propylthiophenethylamine (2CT-7). The tryptamines examined were 5-methoxy- $N, N$-dimethyltryptamine (5-MeO-DMT), $\alpha$-methyltryptamine (AMT), $N$ isopropyl-5-methoxy- $N$-methyltryptamine (5-MeOMIPT), and $N, N$-diisopropyl-5-methoxytryptamine (5-MeO-DIPT). As the reference standards, five compounds were newly synthesized, and five were purified from the products. These were all structurally ascertained by GC-MS and nuclear magnetic resonance (NMR) spectroscopy. Between April 2005 and March 2007, 8 compounds analyzed in this study were found in 100 out of the 178 products which were examined.

Key words — designer drug, hallucinogen, phenethylamine, tryptamine, nuclear magnetic resonance, quantitative analysis

\footnotetext{
*To whom correspondence should be addressed: Tokyo Metropolitan Institute of Public Health, 3-24-1 Hyakunin-cho, Shinjuku-ku, Tokyo 169-0073, Japan. Tel.: +81-3-3363-3231; Fax: +81-3-3368-4060; E-mail: Misako_Takahashi@member. metro.tokyo.jp
}

\section{INTRODUCTION}

"Designer drugs" or "abused drugs," which are known to cause euphoria and hallucination, when marketed, include the drugs mentioned above in addition to a variety of similar chemically synthesized drugs as well as drugs derived from plants and plant parts such as mushrooms, seeds, and leaves. "Designer drugs" are readily available on the market and can be purchased via the internet; therefore, there is a growing concern that drug abuse has increased due to the fact that it is spreading among the youth. Further, since the components, dosage, and usage of "designer drugs" are unclear, their abuse may damage health and cause harmful symptoms and side effects such as vomiting, headache, memory disorders, and drug psychosis; even social damage might result from hypnotic drug abuse. In order to prevent such damage, it is necessary to analyze and identify the components of such drugs, inform people of the associated risks, and immediately regulate them in case they are deemed to be illegal. However, as there are several types of such drugs, and it is difficult to obtain standards for them; currently, analytical methods ${ }^{1-6)}$ have been established for a few drugs. Thus, the aim of this study was to develop sufficiently sensitive identification and quantification methodology for hallucinogenic drugs in commercial products.

In the present study, we chose the following ten compounds (Fig. 1) as the analytical targets because in our institute we frequently experienced the drug cases which they were determined using mass spectrometry (MS) and nuclear magnetic resonance (NMR). These were as follows: 3,4,5-trimethoxyamphetamine (TMA) and 4-bromo-2,5-dimethoxyphenethylamine (2C-B), which are phenethylamine hallucinogens and have been recently designated as narcotic drugs; and 2,4,5-trimethoxyamphetamine (TMA-2), 4-iodo-2,5-dimethoxyphenethylamine (2C-I), 2,5-dimethoxy-4-ethylthiophenethylamine (2CT2), ${ }^{7}$ 2,5-dimethoxy-4-propylthiophenethylamine (2CT-7), ${ }^{7-9)}$ and four designer tryptamines that are their analogs with similar hallucinatory effects. The four designer tryptamines ${ }^{10,11)}$ are 5methoxy- $N, N$-dimethyltryptamine (5-MeO-DMT), $\alpha$-methyltryptamine (AMT), $N$-isopropyl-5-methoxy- $N$-methyltryptamine (5-MeO-MIPT), and $\mathrm{N}, \mathrm{N}$-diisopropyl-5-methoxytryptamine (5-MeODIPT). TMA, TMA-2, 2C-B, 2CT-2, and 2CT7 were synthesized (Fig. 2). 2C-I and four 
<smiles>COc1cc(CC(C)C(C)C(C)C)cc(OC)c1OC</smiles><smiles>COc1cc(OC)c(OC)cc1CC(C)C(C)N</smiles><smiles>COc1cc(CCCN)c(OC)cc1Br</smiles>

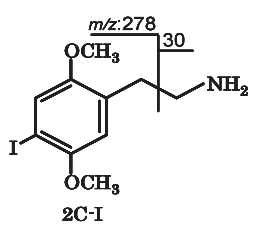

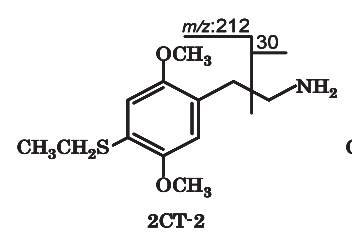

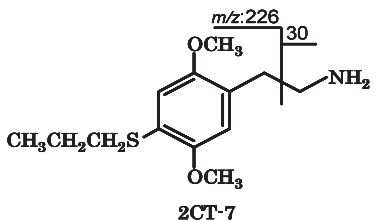<smiles>COc1ccc2[nH]cc(CCCN(C)C)c2c1</smiles><smiles>CC(N)Cc1c[nH]c2ccccc12</smiles><smiles>COc1ccc2[nH]cc(CCCN(C)C(C)C)c2c1</smiles><smiles>COc1ccc2[nH]cc(CCCN(C(C)C)C(C)C)c2c1</smiles>

Fig. 1. Structures and Fragment Ions

tryptamines were isolated and purified from products purchased on the market. We considered the "designer drugs"12,13) purchased in the past three years for which analytical methods are established. The proposed method using gas chromatographymass spectrometry (GC-MS) was useful for the determination of drug abuse, sufficiently sensitive and simultaneous.

\section{MATERIALS AND METHODS}

Reagents — Chemicals: AMT (> 99\%) was sourced from Aldrich (Mil, WI, U.S.A). Nitroethane, acetic acid, ammonium acetate, tetrahydrofuran (THF), $\mathrm{LiAlH}_{4}$, hydrochloric acid, dichloromethane, ethyl bromide, $\mathrm{N}$ methylformanilide, chloroform, acetonitrile, and methanol (all of analytical grade) were purchased from Wako (Osaka, Japan). Water was purified using a Milli-Q water purification unit (Nihon Millipore, Tokyo, Japan).

Test solutions: These were prepared according to the General Tests and General Notices of the
Japanese Pharmacopoeia. ${ }^{14)}$

Samples — 178 products purchased at adult shops or via the Internet over the past two years in Japan were used as samples.

Preparation of Standards from the Products - 2C-I, 5-MeO-DMT, 5-MeO-MIPT, and 5$\mathrm{MeO}-\mathrm{DIPT}$ were separated and purified from "designer drugs" on the market. The purified compounds were ascertained by GC-MS and NMR.

Separation and Clean-up-2C-I, 5-MeODMT, 5-MeO-MIPT, and 5-MeO-DIPT: Each of these commercial products was dissolved in $0.02 \mathrm{~mol} / 1$ hydrochloric acid. Extractions were then performed with chloroform from the ammonia alkaline solutions and the chloroform layer was filtered. The filtrate was evaporated to remove the solvent and purified 2C-I, 5-MeO-DMT, 5-MeO-MIPT, and 5-MeO-DIPT were then obtained for use.

Synthesis of Standards — TMA-2, TMA, 2C-B, 2CT-2, and 2CT-7 were synthesized (Fig. 2). ${ }^{15,16)}$ The synthesized compounds were ascertained by GC-MS and NMR.

Synthesis — TMA-2, TMA, 2C-B, 2CT-2, and 2CT-7 were synthesized as follows by the method of Shulgin. ${ }^{15)}$

TMA-2: A solution of [a]-1 $(2.5 \mathrm{~g}, 12.7 \mathrm{mmol})$ in nitroethane was refluxed in the presence of acetic acid and ammonium acetate for $2 \mathrm{hr}$. The excess nitroethane was removed, and the deep orange oily residue was drained. These were washed with $\mathrm{MeOH}$ and air dried. A yellow needle-like crystal, [a]-2, was then obtained by the usual method. After dissolving [a]-2 in THF and adding $\mathrm{LiAlH}_{4}$ in anhydrous $\mathrm{Et}_{2} \mathrm{O}$, the solution was refluxed for $4 \mathrm{hr}$. The excess $\mathrm{LiAlH}_{4}$ was subsequently decomposed, and the solution was filtered after treatment with potassium sodium tartrate. The filtrate was evaporated under vacuum and concentrated hydrochloric acid was added to form TMA-2 hydrochloride (1.4 g, yield of $42 \%)$.

TMA: The same procedure as that followed for TMA-2 hydrochloride was followed, using [a]-1 $(4.0 \mathrm{~g}, 20 \mathrm{mmol})$ as a starting material. There was an immediate formation of the anhydrous salt TMA hydrochloride (1.5 g, yield of 30\%)

2C-B: A solution of [b]-1 $(5 \mathrm{~g}, 32 \mathrm{mmol})$ in nitromethane was refluxed in the presence of anhydrous ammonium acetate for $2.5 \mathrm{hr}$, the residue crystallized spontaneously. This crude nitrostyrene was purified by grinding with isopropyl alcohol (IPA), filtering, and the air-drying to obtain 2,5dimethoxy- $\beta$-nitrostyrene. [b]-2 was obtained by 
[a]<smiles>Cc1cc(C)c(N)c(N)c1C</smiles><smiles>CC(C)=Cc1cc(C)c(Cl)c(Br)c1N</smiles><smiles>Cc1cc(C)c(CC(C)N)c(N)c1N</smiles>

[b]

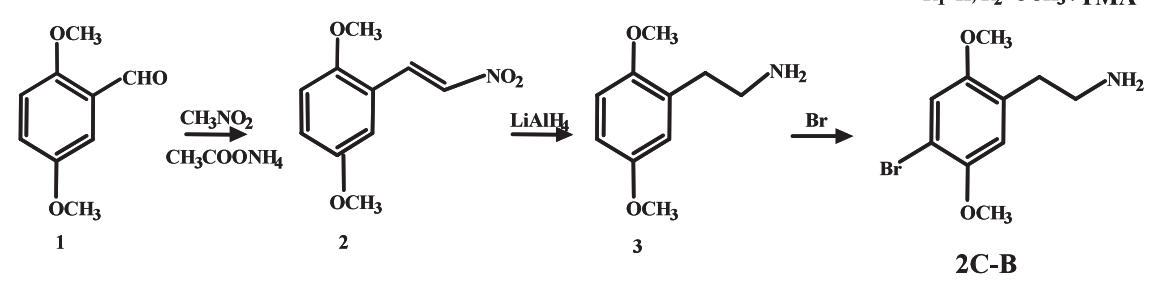

[c]
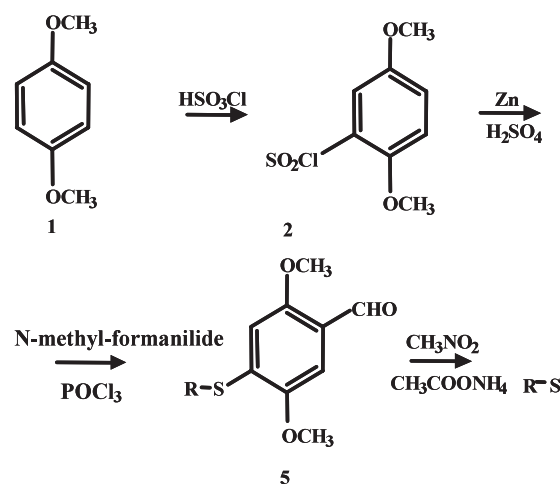<smiles>COc1ccc(OC)c(OC)c1</smiles>

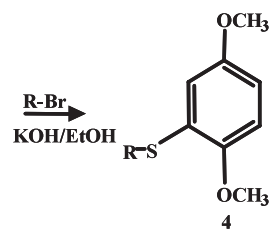

3 4

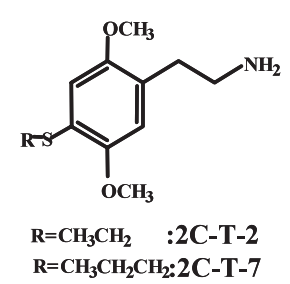

Fig. 2. Synthesis of Phenethylamines

the usual method. The same procedures as those followed for TMA-2 were followed for [b]-2 to yield [b]-3. To [b]-3 in glacial acetic acid was added elemental bromine dissolved in acetic acid to yield the hydrobromide. The entire mass of acetic acid was dissolved in warm $\mathrm{H}_{2} \mathrm{O}$, basified to $\mathrm{pH} 11$ with $25 \%$ $\mathrm{NaOH}$, and extracted with $\mathrm{CH}_{2} \mathrm{Cl}_{2}$. After removal of the solvent, the obtained residue was distilled. The resulting white oil was dissolved in $\mathrm{H}_{2} \mathrm{O}$ containing acetic acid. This clear solution was treated with concentrated hydrochloric acid, which resulted in the immediate formation of the anhydrous salt, 2C-B hydrochloride (1.8 g, yield of 19\%).

2CT-2: Dichloromethane and chlorosulfonic acid were added to [c]-1 (10 g, $72 \mathrm{mmol})$ and extraction with dichloromethane was carried out to obtain [c]-2. To a solution of $40 \mathrm{ml} 25 \% \mathrm{H}_{2} \mathrm{SO}_{4}(\mathrm{v} / \mathrm{v})$ was added [c]-2 (9.8 g), and the mixture was heated on a steam bath. Treatment by the usual method led to the formation of [c]-3 $(9 \mathrm{~g})$. This was ethylated with ethyl bromide in alkaline ethanol ([c]-4), to which $\mathrm{N}$-methylformanilide was added to yield [c]-5. To a solution of [c]-5 in nitromethane was added anhydrous ammonium acetate, and the mixture was heated on a steam bath. The excess nitromethane was removed, and the residue crystallized spontaneously ([c]-6). A suspension of $\mathrm{LiAlH}_{4}$ in anhydrous THF was added to [c]-6 in a little THF, and the mixture was held at reflux. This was dissolved in $80 \mathrm{ml}$ IPA and added to concentrated hydrochloric acid, forming immediate crystals of 2CT-2 hydrochloride (2.8 g, yield of $13 \%)$.

2CT-7: The same procedure as that followed for 2CT-2 was carried out for [c]-1 (10 g, $72 \mathrm{mmol})$, which was used as a starting material, and [c]-2 and [c]-3 were produced. Further, [c]-3 was reacted with propyl bromide to afford [c]-4. The same procedures were followed to obtain 2CT-7 hydrochloride (3.5 g, yield of $17 \%$ ).

Spectral Data of Standards — The synthesized compounds (TMA-2, TMA, 2C-B, 2CT-2, and 2CT7) and purified compounds (2C-I, 5-MeO-DMT, 5MeO-MIPT, and 5-MeO-DIPT) were identified by Electron impact-MS and NMR. The spectral data were as follows.

TMA-2: EI/MS $(m / z, \%): 225\left(\mathrm{M}^{+}, 3.1\right), 182$ (100), 167 (32.6), 151 (11.6), 139 (7.4), 44 (5.9). ${ }^{1} \mathrm{H}-\mathrm{NMR}\left(\mathrm{CD}_{3} \mathrm{OD}, \delta\right): 1.11(3 \mathrm{H}, \mathrm{d}, J=6.3 \mathrm{~Hz})$, $2.48(1 \mathrm{H}, \mathrm{dd}, J=13.2,8.1 \mathrm{~Hz}), 2.67(1 \mathrm{H}, \mathrm{dd}, J$ = 13.3, $5.3 \mathrm{~Hz}), 3.16(1 \mathrm{H}, \mathrm{m}), 3.79(3 \mathrm{H}, \mathrm{s}), 3.83$ 
(3 H, s), $3.88(3 \mathrm{H}, \mathrm{s}), 6.53(1 \mathrm{H}, \mathrm{s}), 6.70(1 \mathrm{H}, \mathrm{s})$.

${ }^{13} \mathrm{C}-\mathrm{NMR}\left(\mathrm{CD}_{3} \mathrm{OD}, \delta\right): 23.4,40.4,47.3,56.2,56.2$,

56.6, 97.7, 115.1, 119.5, 142.7, 148.0, 151.8.

TMA: EI/MS $(m / z, \%): 225\left(\mathrm{M}^{+}, 1\right), 182(35)$, 167 (12.5), 151 (3.2), 44 (100). ${ }^{1} \mathrm{H}-\mathrm{NMR}\left(\mathrm{CD}_{3} \mathrm{OD}\right.$, $\delta): 1.28(3 \mathrm{H}, \mathrm{d}, J=6.3 \mathrm{~Hz}), 2.79(1 \mathrm{H}, \mathrm{dd}, J=$ $13.8,8.0 \mathrm{~Hz}), 2.87(1 \mathrm{H}, \mathrm{dd}, J=13.5,6.8 \mathrm{~Hz}), 3.54$ $(1 \mathrm{H}, \mathrm{m}), 3.74(3 \mathrm{H}, \mathrm{s}), 4.85(6 \mathrm{H}, \mathrm{s}), 6.56(2 \mathrm{H}, \mathrm{s})$. ${ }^{13} \mathrm{C}-\mathrm{NMR}\left(\mathrm{CD}_{3} \mathrm{OD}, \delta\right)$ : $18.6,42.1,49.5,56.7,56.7$, 61.0, 107.7, 107.7, 133.3, 138.4, 154.9, 154.9.

2C-B: EI/MS $(m / z, \%): 260\left(\mathbf{M}^{+}, 14\right), 230$ (100), 217 (22.2), 201 (8.5), 105 (9.5), 77 (16.4). ${ }^{1} \mathrm{H}-\mathrm{NMR}\left(\mathrm{CD}_{3} \mathrm{OD}, \delta\right): 2.95(2 \mathrm{H}, \mathrm{t}, J=7.4 \mathrm{~Hz})$, $3.15(2 \mathrm{H}, \mathrm{t}, J=7.4 \mathrm{~Hz}), 3.81(3 \mathrm{H}, \mathrm{s}), 3.83(3 \mathrm{H}, \mathrm{s})$, $6.91(1 \mathrm{H}, \mathrm{s}), 7.26(1 \mathrm{H}, \mathrm{s}) .{ }^{13} \mathrm{C}-\mathrm{NMR}\left(\mathrm{CD}_{3} \mathrm{OD}, \delta\right)$ : 29.8, 40.6, 56.6, 57.4, 111.5, 116.3, 117.3, 126.2, 151.7, 153.4.

2CT-2: EI/MS $(m / z, \%): 241\left(\mathbf{M}^{+}, 30\right), 212$ (100), 183 (40), 153 (22.5), 59 (8). ${ }^{1} \mathrm{H}-\mathrm{NMR}$ $\left(\mathrm{CD}_{3} \mathrm{OD}, \delta\right): 1.18(3 \mathrm{H}, \mathrm{t}, J=7.4 \mathrm{~Hz}), 2.73(2 \mathrm{H}$, $\mathrm{t}, J=7.4 \mathrm{~Hz}), 2.76(2 \mathrm{H}, \mathrm{q}, J=7.4 \mathrm{~Hz}), 2.87(2 \mathrm{H}$, $\mathrm{t}, J=7.4 \mathrm{~Hz}), 3.79(3 \mathrm{H}, \mathrm{s}), 3.80(3 \mathrm{H}, \mathrm{s}), 6.57(1 \mathrm{H}$, s), $6.89(1 \mathrm{H}, \mathrm{s}) .{ }^{13} \mathrm{C}-\mathrm{NMR}\left(\mathrm{CD}_{3} \mathrm{OD}, \delta\right): 14.3,26.9$, $34.4,42.1,56.2,56.5,113.8,113.9,122.3,127.1$, 151.7, 151.9.

2CT-7: EI/MS $(m / z, \%): 255\left(\mathrm{M}^{+}, 35\right), 226$ (100), 183 (50), 153 (22.5), 58 (25). ${ }^{1} \mathrm{H}-\mathrm{NMR}$ $\left(\mathrm{CD}_{3} \mathrm{OD}, \delta\right): 1.23(3 \mathrm{H}, \mathrm{t}, J=7.4 \mathrm{~Hz}), 1.62(2 \mathrm{H}, \mathrm{m})$, $2.87(2 \mathrm{H}, \mathrm{t}, J=7.1 \mathrm{~Hz}), 2.94(2 \mathrm{H}, \mathrm{t}, J=7.4 \mathrm{~Hz})$, $3.13(2 \mathrm{H}, \mathrm{t}, J=7.4 \mathrm{~Hz}), 3.82(3 \mathrm{H}, \mathrm{s}), 3.83(3 \mathrm{H}$, s), $6.8(1 \mathrm{H}, \mathrm{s}), 6.91(1 \mathrm{H}, \mathrm{s}) .{ }^{13} \mathrm{C}-\mathrm{NMR}\left(\mathrm{CD}_{3} \mathrm{OD}\right.$, $\delta): 13.5,22.7,34.8,34.9,42.3,56.2,56.5,113.8$, 113.9, 122.5, 127.3, 151.8, 152.0.

2C-I: EI/MS $(m / z, \%): 307\left(\mathbf{M}^{+}, 15\right), 278(100)$, 263 (19.0), 247 (6.4), 180 (2.7), 105 (4.5). ${ }^{1} \mathrm{H}-\mathrm{NMR}$ $\left(\mathrm{CDCl}_{3}, \delta\right): 2.72(2 \mathrm{H}, \mathrm{t}, J=6.9 \mathrm{~Hz}), 2.91(2 \mathrm{H}, \mathrm{t}$, $J=6.9 \mathrm{~Hz}), 3.77(3 \mathrm{H}, \mathrm{s}), 3.83(3 \mathrm{H}, \mathrm{s}), 6.67(1 \mathrm{H}$, s), $7.22(1 \mathrm{H}, \mathrm{s}) .{ }^{13} \mathrm{C}-\mathrm{NMR}\left(\mathrm{CDCl}_{3}, \delta\right): 30.2,40.7$, 56.6, 57.5, 64.8, 114.9, 123.0, 127.3, 153.6, 154.3.

5-MeO-DMT: EI/MS $(\mathrm{m} / \mathrm{z}, \%): 218\left(\mathrm{M}^{+}, 10\right)$, 160 (6.3), 145 (2.5), 117 (5.0), 58 (100), 42 (4). ${ }^{1} \mathrm{H}-\mathrm{NMR}\left(\mathrm{CDCl}_{3}, \delta\right): 2.34(6 \mathrm{H}, \mathrm{s}), 2.63(2 \mathrm{H}, \mathrm{m})$, $2.91(2 \mathrm{H}, \mathrm{m}), 3.86(3 \mathrm{H}, \mathrm{s}), 6.85(1 \mathrm{H}, \mathrm{dd}, J=2.3$, $8.6 \mathrm{~Hz}), 6.98(1 \mathrm{H}, \mathrm{br} \mathrm{d}, J=2.3 \mathrm{~Hz}), 7.05(1 \mathrm{H}, \mathrm{d}$, $J=2.3 \mathrm{~Hz}), 7.22(1 \mathrm{H}, \mathrm{d}, J=8.6 \mathrm{~Hz}) .{ }^{13} \mathrm{C}-\mathrm{NMR}$ $\left(\mathrm{CDCl}_{3}, \delta\right): 23.7,45.4,56.0,60.1,100.8,111.8$, 112.1, 113.9, 122.3, 127.8, 131.5, 153.9.

5-MeO-MIPT: EI/MS $(m / z, \%): 246\left(\mathrm{M}^{+}, 4\right)$, 174 (4), 159 (6), 86 (100), 44 (24.2). ${ }^{1} \mathrm{H}-\mathrm{NMR}$ $\left(\mathrm{CDCl}_{3}, \delta\right): 1.06(6 \mathrm{H}, \mathrm{d}, J=6.9 \mathrm{~Hz}), 2.36(3 \mathrm{H}, \mathrm{s})$, $2.73(2 \mathrm{H}, \mathrm{m}), 2.90(2 \mathrm{H}, \mathrm{m}), 2.94(1 \mathrm{H}$, septet, $J=$ $6.9 \mathrm{~Hz}), 3.86(3 \mathrm{H}, \mathrm{s}), 6.85(1 \mathrm{H}, \mathrm{dd}, J=8.6,2.3 \mathrm{~Hz})$,
$7.00(1 \mathrm{H}$, br s $), 7.06(1 \mathrm{H}, \mathrm{d}, J=2.3 \mathrm{~Hz}), 7.24(1 \mathrm{H}$, $\mathrm{d}, J=8.6 \mathrm{~Hz}) .{ }^{13} \mathrm{C}-\mathrm{NMR}\left(\mathrm{CDCl}_{3}, \delta\right): 18.0,24.2$, 37.1, 53.6, 54.1, 56.0, 100.9, 111.8, 112.1, 114.5, 122.3, 128.0, 131.5, 153.9.

5-MeO-DIPT: EI/MS $(m / z, \%): 274\left(\mathrm{M}^{+}, 0.5\right)$, 174 (4), 159 (22), 114 (100), 72 (20). ${ }^{1} \mathrm{H}-\mathrm{NMR}$ $\left(\mathrm{CDCl}_{3}, \delta\right): 1.08(12 \mathrm{H}, \mathrm{d}, J=6.3 \mathrm{~Hz}), 2.72(2 \mathrm{H}$, m), $2.83(2 \mathrm{H}, \mathrm{m}), 3.12(2 \mathrm{H}$, septet, $J=6.3 \mathrm{~Hz})$, $3.86(3 \mathrm{H}, \mathrm{s}), 6.85(1 \mathrm{H}, \mathrm{dd}, J=2.9,8.6 \mathrm{~Hz}), 7.00$ $(1 \mathrm{H}$, br d, $J=1.7 \mathrm{~Hz}), 7.08(1 \mathrm{H}, \mathrm{d}, J=2.9 \mathrm{~Hz})$, $7.24(1 \mathrm{H}, \mathrm{d}, J=8.6 \mathrm{~Hz}) .{ }^{13} \mathrm{C}-\mathrm{NMR}\left(\mathrm{CDCl}_{3}, \delta\right)$ : 20.8, 28.2, 46.5, 49.0, 55.9, 101.0, 111.7, 112.0, $115.1,122.1,128.1,131.4,153.9$.

NMR $-{ }^{1} \mathrm{H}$ - and ${ }^{13} \mathrm{C}$-NMR spectra were obtained on a JEOL (Tokyo, Japan) JNM-ECA500 instrument at $500 \mathrm{MHz}$ and $125 \mathrm{MHz}$, respectively, with Tetra-methyl-silane as the internal standard. NMR: Approximately $10.0 \mathrm{mg}$ of each sample was dissolved in $1 \mathrm{ml}$ of heavy methanol or chloroform.

Sample Preparation — As described below, test solutions were prepared for the synthetic and commercial powdered samples and $0.1 \mathrm{ml}$ of the samples was distilled to prepare test solutions for the commercial liquid products. GC-MS: Approximately $10.0 \mathrm{mg}$ of each sample was dissolved in $20 \mathrm{ml}$ of methanol. The solvent was diluted ten times with acetonitrile.

GC-MS — GC-MS was performed on a HP 5963 mass-selective detector interfaced with a HP 6890 series GC. The instrument used was an Agilent N3520 (Agilent Technologies Japan Ltd., Tokyo, Japan). GC conditions; DB-5MS capillary column $(30 \mathrm{~m} \times 0.25 \mathrm{~mm}$ i.d., $0.25 \mu \mathrm{m}$ film thickness, Agilent Technologies, Palo Alto, CA, U.S.A), carrier gas: helium, flow-rate $1.1 \mathrm{ml} / \mathrm{min}$, oven temperature from $130^{\circ} \mathrm{C}(5 \mathrm{~min})$ to $290^{\circ} \mathrm{C}$ at $10^{\circ} \mathrm{C} / \mathrm{min}$ $20 \mathrm{~min}$ isotherm, injector temperature $250^{\circ} \mathrm{C}$, splitless, transfer line $290^{\circ} \mathrm{C}$. MS conditions; electron impact ionization, full scan at $m / z 30-350$, electron energy $70 \mathrm{eV}$, ion source temperature $200^{\circ} \mathrm{C}$, injection volume $1 \mu$ l.

\section{RESULTS AND DISCUSSION}

\section{GC-MS of Standard Compounds}

The ten components were well separated in the GC (Fig. 3). The EI mass spectra resulting from the GC-MS analysis of the phenethylamines and tryptamines are presented in Fig. 4 . Figure 4 describes the fragmentation patterns. The $\alpha$-fission process is expected to produce fragment $\mathrm{m} / \mathrm{z} 44$ 


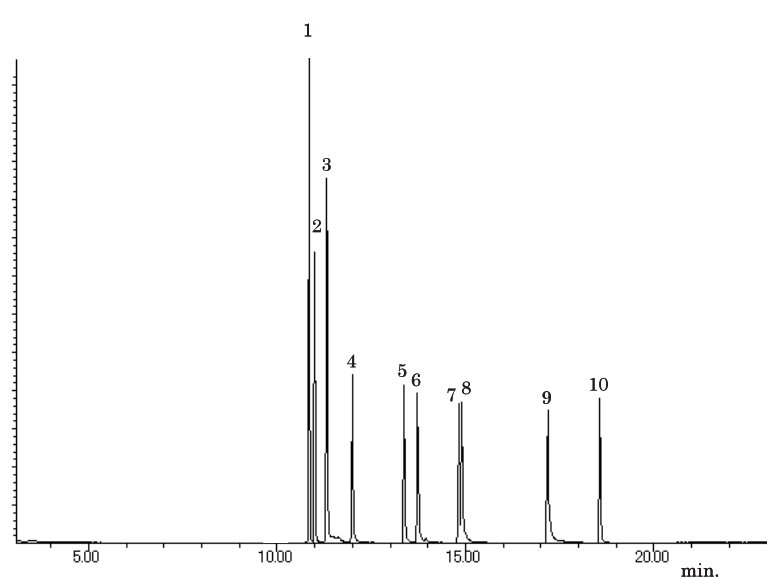

Fig. 3. GC-MS (TIC) Chromatogram of Phenethylamines and Tryptamines

The injection volume of $1 \mu \mathrm{l}$ containing a concentration of $0.05 \mathrm{mg} / \mathrm{ml}$ of each standards. 1: TMA, 2: TMA-2, 3: AMT, 4: 2C-B, 5: 2C-I, 6: 2CT-2, 7: 5-MeO-DMT, 8: 2CT-7, 9: 5-MeO-MIPT, 10: 5-MeO-DIPT.
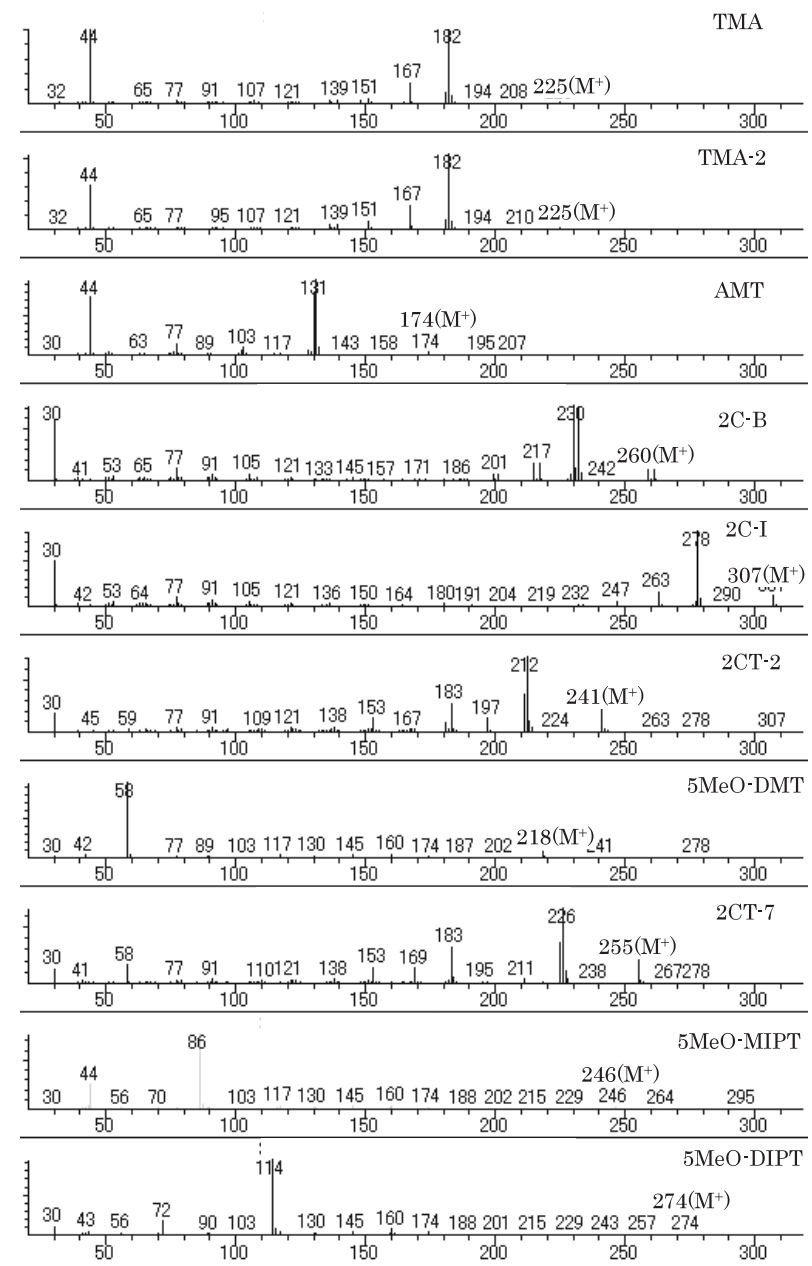

Fig. 4. EI Mass Spectra of Phenethylamines and Tryptamines for TMA, TMA-2, and AMT, ${ }^{5)}$ fragment $m / z 30$ for 2C-B, 2C-I, 2CT-2, and 2CT-7; fragment $\mathrm{m} / \mathrm{z}$ 58 for 5-MeO-DMT; ${ }^{11)}$ fragment $m / z 86$ for 5 MeO-MIPT; ${ }^{11)}$ and fragment $\mathrm{m} / z 114$ for $5-\mathrm{MeO}$ DIPT. ${ }^{5,11)}$ The predominant abundance of ion $m / z$ 182 in the case of compounds TMA and TMA-2, ion $\mathrm{m} / \mathrm{z} 230$ for $2 \mathrm{C}$-B, ion $\mathrm{m} / \mathrm{z} 278$ for $2 \mathrm{C}$-I, ion $\mathrm{m} / \mathrm{z} 212$ for $2 \mathrm{CT}-2$, ion $\mathrm{m} / \mathrm{z} 226$ for 2CT-7, and ion $m / z 131$ for AMT could be explained by the $\alpha$-fission with hydrogen rearrangement, which produces a phenylalkyl moiety. Similarly, the predominant abundance of ion $m / z 58$ for 5-MeO-DMT, ion $m / z 86$ for 5-MeO-MIPT, and ion $m / z 114$ for 5$\mathrm{MeO}-\mathrm{DIPT}$ could be explained by fragmentation of the typical $N$-terminal aliphatic amines.

The target compounds were determined by GCMS in the scan mode and quantified in the selected ion monitoring mode. Qualifying ions were $m / z 225$ $\left(\mathrm{M}^{+}\right), 167$, and 44 for TMA; $m / z 225\left(\mathrm{M}^{+}\right), 167$, and 44 for TMA-2; $m / z 174\left(\mathrm{M}^{+}\right), 103$, and 44 for AMT; $m / z 260\left(\mathrm{M}^{+}\right), 215$, and 77 for $2 \mathrm{C}-\mathrm{B} ; m / z$ $307\left(\mathrm{M}^{+}\right), 263$, and 77 for $2 \mathrm{C}-\mathrm{I} ; m / z 241\left(\mathrm{M}^{+}\right), 183$, and 153 for 2CT-2; $m / z 218\left(\mathrm{M}^{+}\right), 145$, and 103 for 5-MeO-DMT; $m / z 255\left(\mathrm{M}^{+}\right), 183$, and 58 for 2CT7; $m / z 246\left(\mathrm{M}^{+}\right), 160$, and 145 for 5-MeO-MIPT; $m / z 274\left(\mathrm{M}^{+}\right), 145$, and 72 for 5-MeO-DIPT. Target ions at $m / z 182$ for TMA, $m / z, 182$ for TMA-2, $m / z$ 131 for AMT, $m / z 230$ for $2 \mathrm{C}-\mathrm{B}, m / z 278$ for $2 \mathrm{C}-\mathrm{I}$, $m / z 212$ for 2CT-2, $m / z 58$ for 5-MeO-DMT, $m / z$ 226 for $2 \mathrm{CT}-7, \mathrm{~m} / z 86$ for 5-MeO-MIPT, and $\mathrm{m} / z$ 114 for 5-MeO-DIPT were selected for the quantification. Detection limits of $0.1 \mathrm{ppm}$ were attained by GC-MS (EI) in the selected ion monitoring mode.

The relationships between the peak area $(x)$ and the amount of each component $(y)$ was linear over the range 10-200 ppm and passed through the origin; TMA: $y=1.858 x-0.0328(r=0.999)$, TMA2: $y=0.4156 x-0.048(r=0.998)$, AMT: $y=$ $0.0202 x-0.015(r=0.999), 2 \mathrm{C}-\mathrm{B}: y=0.0092 x-$ $0.42(r=0.999), 2 \mathrm{C}-\mathrm{I}: y=0.067 x+21.7(r=$ 0.999), 2CT-2: $y=52.241 x-30(r=0.999)$, 5MeO-DMT: $y=4.066 x+3.88(r=0.999), 2 \mathrm{CT}-$ $7: y=1.23 x+9.65(r=0.999), 5 \mathrm{MeO}-\mathrm{MIPT}:$ $y=0.095 x+3.00(r=0.999)$, 5MeO-DIPT: $y=$ $0.233 x+7.84(r=0.999)$.

The accuracy of the procedure was determined by spiking a placebo formulation with a known concentration $(50 \mathrm{ppm})$ of the standard. The recoveries were between 92 and $98 \%(n=5)$. The C.V. values $(n=5)$ were between 2 and $5 \%$. 

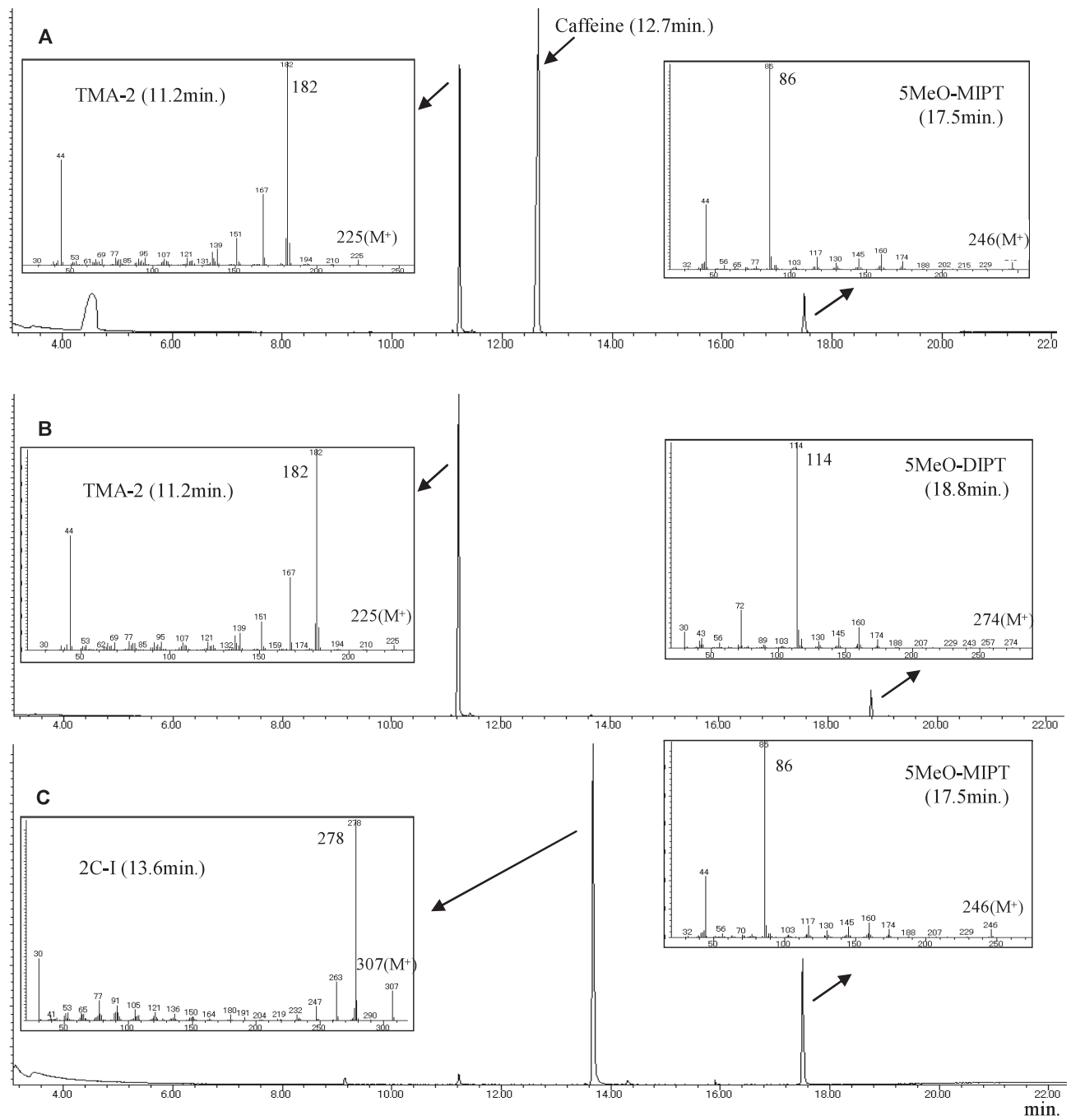

Fig. 5. GC-MS Analyses of the Samples A: No.10, B: No.12, C: No.15.

\section{Analysis of Commercial Products}

The compounds of the commercial products were identified and quantified using hydrochlorides of synthesized compounds TMA-2, TMA, 2C-B, 2CT-2, and 2CT-7, and purified compounds 2CI, 5-MeO-DMT, 5-MeO-MIPT, and 5-MeO-DIPT as the standards by GC-MS. The other methodologies (GC, high-performance liquid chromatography, ultra-violet absorption spectroscopy) were additionally utilized for further identification (data not shown). The quantifications were carried out according to the GC-MS (Selected ion monitoring) tests and the absolute calibration curve method.

Between April 2005 and March 2007, 178 products were purchased from stores and through the internet and were subsequently examined. The products in which either within the ten compounds was detected are listed in Table 1. The results of
Table 1. The Compounds Detected in the 178 Samples

\begin{tabular}{lc}
\hline \hline Detected compounds & No of products \\
\hline TMA & 0 \\
TMA-2 & 12 \\
2C-B & 0 \\
$2 \mathrm{C}-\mathrm{I}$ & 9 \\
$2 \mathrm{CT}-7$ & 4 \\
$2 \mathrm{CT}-2$ & 2 \\
AMT & 4 \\
$5-\mathrm{MeO}-\mathrm{DMT}$ & 7 \\
$5-\mathrm{MeO}-\mathrm{MIPT}$ & 30 \\
$5-\mathrm{MeO}-\mathrm{DIPT}$ & 32 \\
\hline
\end{tabular}

the quantitative analyses of the "designer drugs," which were mixtures of several drugs, are shown in Table 2. In the "designer drugs," several series such as piperazine series, e.g., 1-(3-chlorophyle)- 
Table 2. Determination of Compounds in Designer Drugs

\begin{tabular}{|c|c|}
\hline Products & Detected compounds (mg/mg, $\mathrm{mg} / \mathrm{ml}$ sample) \\
\hline No.1 (powder) & TMA-2 (0.1), 5-MeO-DIPT (0.04), 2-AI ${ }^{a)}$ \\
\hline No.2 (liquid) & 2C-I (1.5), 3TMP ${ }^{b)}$ \\
\hline No.4 (liquid) & $\left.2 \mathrm{C}-\mathrm{I}(0.8), 2 \mathrm{C}-\mathrm{C}^{c}\right)$ \\
\hline No.5 (liquid) & 5-MeO-DIPT (1.2), 5-MeO-DMT (0.3), 3CPP \\
\hline No.6 (liquid) & 5-MeO-DMT (1.2), 3CPP, 4FMP ${ }^{d)}$ \\
\hline No.7 (liquid) & 5-MeO-AMT (1.2), 5-MeO-DIPT (1.2) \\
\hline No.8 (liquid) & $\left.\operatorname{AMT}(0.8), 1,4-\mathrm{BD}^{e}\right)$ \\
\hline No.9 (liquid) & 5-MeO-DIPT (0.1), 5-MeO-MIPT (0.05), MBZP $\left.{ }^{f}\right)$ \\
\hline No.10 (liquid) & TMA-2 (0.2), 5-MeO-MIPT (0.02), Caffeine \\
\hline No.11 (powder) & 5-MeO-DIPT (0.02), 5-MeO-MIPT (0.01), Caffeine \\
\hline No.12 (powder) & TMA-2 (3.3), 5-MeO-DIPT (0.3) \\
\hline No.13 (liquid) & TMA-2 (0.5), 5-MeO-MIPT (1.2), 3CPP \\
\hline No.14 (powder) & TMA-2 (0.2), 5-MeO-MIPT (0.5), 3CPP \\
\hline No.15 (powder) & 2C-I (0.7), 5-MeO-MIPT (0.2) \\
\hline
\end{tabular}

piperazine (3CPP), phenethylamine series, and tryptamine series were mixed in variable amounts. The analytical results of No. 10, 12 and 15 obtained by using GC-MS are shown in Fig. 5. TMA and 2C$\mathrm{B}$ were not detected.

In conclusions, the efficacy of the test methods for identifying and quantifying the ten phenethylamine and tryptamine compounds was examined by testing the hallucinogens used for the so-called "designer drugs" or "abused drugs." Since it was difficult to obtain standards for any of the components, the synthetic compounds and isolated and purified compounds were used as the standards for the tests. The results revealed the ten compounds to be satisfactorily identified and simultaneously quantified using MS. GC-MS (SIM) method was found to be sufficiently sensitive for the determination of the ten compoumds in the range of micrograms using $10 \mathrm{mg}$ samples. Although all the components used in the present study are regulated by various legislations (the "Narcotics and Stimulants Control Law" and the "Pharmaceutical Affairs Law"), there are several analogs such as 2C-C: 4-chloro-2,5-dimethoxyphenethylamine, 2C-E: 2,5dimethoxy-4-ethylphenethylamine, and 2CT-4: 2,5dimethoxy-4-isopropylthiophenethylamine. Therefore, the present analytical method should be further examined to deal with these compounds.

Acknowledgements This work was supported in part by MEXT. HAITEKU (2005-2007).

\section{REFERENCES}

1) Bell, S. E. J., Burns, D. T., Dennis, A. C. and Speers, J. S. (2000) Rapid analysis of ecstasy and related phenethylamines in seized tablets by Raman spectroscopy. Analyst, 125, 541-544.

2) Aalberg, L., Deruiter, J., Clark, C. R., Noggele, F. T. and Sippola, E. (2003) Chromatographic and spectroscopic methods of identification for the side-chain regioisomers of 3,4-methylenedioxyphenethylamines related to MDEA, MDMMA and MBDB. J. Chromatogr. Sci., 41, 227-233.

3) Brandt, S. D., Freeman, S., Fleet, I. A., McGagh, P. and Alder, J. F. (2004) Analytical chemistry of synthetic routes to psychoactive tryptamines. Part 1. Characterization of the Speeter and Anthony synthetic route to 5-methoxy-N,Ndiisopropyltryptamine using ESI-MS-MS and ESITOF-MS. Analyst, 129, 1047-1057.

4) Boatto, G., Nieddu, M., Carta, A., Pau, A., Palomba, M., Asproni, B. and Cerri, R. (2005) Determination of amphetamine-derived designer drugs in human urine by SPE extraction ad capillary electrophoresis with mass spectrometry detection. $J$. Chromatogr. B, 814, 93-98.

5) Kikura-Hanajiri, R., Hayashi, M., Saisho, K. and Goda, Y. (2005) Simultaneous determination of nineteen hallucinogenic tryptamines/ $\beta$-calbolines and phenerhylamines using gas chromatographymass spectrometry and liquid chromatographyelectrospray ionization-mass spectrometry. J. Chromatogr. B, 825, 29-37. 
6) Praisler, M., Dirinck, I., Van Bocxlaer, J., De LeenHeer, A. and Massart, D. L. (2000) Pattern recognition techniques screening for drugs of abuse with gas chromatography-Fourier transform infrared spectroscopy. Talanta, 53, 177-193.

7) De Boer, D. and Bosman, I. (2004) A new trend in drugs-of-abuse; the 2C-series of phenethylamine designer drugs. Pharm. World Sci., 26, 110-113.

8) Curtis, B., Kemp, P., Harty, L., Choi, C. and Christensen, D. (2003) Postmortem identification and quantitation of 2,5-dimethoxy-4-npropylthiophenethylamine using GC-MSD and GCNPD. J. Anal. Toxicol., 27, 493-498.

9) Matsumoto, T., Kikura-Hanajiri, R., Kamakura, H., Kawahara, N. and Goda, Y. (2006) Identification of $N$-methyl-4-(3,4-methylenedioxyphenyl)butan2-amine, distributed as MBDB. J. Health Sci., 52, 805-810.

10) Zimmerman, M. M. (2003) The Identification of 5methoxy-alpha-methyltryptamine (5-MeO-AMT). Microgram J., 1, 158-161.

11) Spratley, T. K., Hays, P. A., Geer, L. C.,
Cooper, S. D. and McKibben, T. D. (2005) Analytical profiles for five "Designer" tryptamines. Microgram J., 3, 54-68.

12) Bell, S. E. J., Burns, D. T., Dennis, A. C., Matchett, L. J. and Speers, J. S. (2000) Composition profiling of seized ecstasy tablets by Raman spectroscopy. Analyst, 125, 1811-1815.

13) Praisler, M., Bocxlaer, J. V., Leenheer, A. D. and Massart, D. L. (2002) Chemometric detection of thermally degraded samples in the analysis of drugs of abuse with gas chromatography-Fouriertransform infrared spectroscopy. J. Chromatogr. A, 962, 161-173.

14) Ministry of Health, Labour and Welfare (2006), Japan Pharmacopoeia 15th ed. with commentary, p. 135.

15) Shulgin, A. T. and Shulgin, A. (1991) PIHKAL A Chemical Love Story, Transform Press, Berkeley, CA.

16) Blachut, D., Czarnocki, Z. and Wojtasiewicz, K. (2001) $\alpha$-Phenylethylamine in illegally produced amphetamine. Forensic Sci. Int., 123, 182-190. 